\title{
Grupo de Pesquisa Computação Afetiva (CA)
}

\author{
Fabrícia Damando Santos ${ }^{1,2}$, Cícero C. Quarto ${ }^{1,3}$, Magda Bercht ${ }^{1}$ \\ ${ }^{1}$ Universidade Federal do Rio Grande do Sul (UFRGS) \\ Caixa Postal 15.064 - 91.501-970 - Porto Alegre - RS - Brazil \\ ${ }^{2}$ Universidade Estadual do Rio Grande do Sul (UERGS) \\ Engenharia da Computação - Guaíba- RS - BBrazil \\ ${ }^{3}$ Centro de Ciências Tecnológicas - Universidade Estadual do Maranhão (UEMA) \\ Caixa Postal 09 - São Luís - MA - Brazil
}

fabriciadamando@gmail.com, cicerodengcomp.uema.br, berchteinf.ufrgs.br

O Grupo de Computação Afetiva (CA), do Programa de Pós-Graduação em Informática na Educação (PPGIE/CINTED), da UFRGS foi criado em 2005, trabalha com a investigação e aplicações da Computação Afetiva no contexto educacional. Tem como objetivos estudar a afetividade no contexto da Inteligência Artificial (IA) e da Informática na Educação; pesquisar as dimensões da afetividade para o desenvolvimento de sistemas; pesquisar e desenvolver técnicas para avaliar, modelar e desenvolver sistemas computacionais aplicados à educação que tenham por função a identificação, expressão e raciocínio sobre e de emoções em interações com agentes artificiais e biológicos.

A área de concentração inclui a investigação da influencia da afetividade na interação virtual, estudo e aplicação de teorias sobre afetividade no foco dos atores do processo e ensino-aprendizagem, na expressão afetiva dos sistemas e agentes artificiais. Suas linhas de pesquisa são: Afetos e emoção em máquina, Ambientes Virtuais de Ensino e Aprendizagem (AVEA), Mineração Dados Educacionais, Pesquisa e Aplicação em Sistemas de Ensino e Aprendizagem e aplicações com uso de técnicas como redes bayesianas, redes neurais artificiais e lógica fuzzy.

Os principais projetos desenvolvidos incluem: Detecção da frustração na aprendizagem de algoritmos, Mapeamento de aspectos afetivos em AVEA; Identificação de presença social em AVEA; Identificação do interesse do aluno em ambientes EaD; Inferência do estado de ânimo desanimado do aluno; Mapeamento de variáveis positivas no contexto de aprendizagem colaborativa. Alguns trabalhos foram premiados, incluindo o prêmio Capes de melhor tese interdisciplinar e melhor artigo no $23^{\circ} \mathrm{SBIE}$, 2012. Também há parcerias e projetos com fomentos: a SEAD - Secretaria de Educação a Distância/UFRGS, Fundação de Amparo à Pesquisa do Estado do Maranhão (FAPEMA) e CNPq.

Ao contar com uma equipe inter e multidisciplinar há pesquisadores doutores, alunos de doutorado e bolsistas de graduação, vindos de diferentes áreas do conhecimento como da Ciência da Computação, Psicologia e Educação. 